\title{
Reconstructive surgery in recurrent deformity (clubfoot relapse)
}

\author{
P. Lascombes ${ }^{1}$, D.A. Popkov², S.S. Leonchuk ${ }^{2}$ \\ ${ }^{1}$ University of Nancy, France; Geneva University Hospitals, Geneva, Switzerland \\ ${ }^{2}$ Ilizarov National Medical Research Centre for Traumatology and Orthopedics, Kurgan, Russian Federation
}

\begin{abstract}
Introduction Recurrent clubfoot deformity may be due to either an imperfect initial correction, or a natural history of a severe disease. In the later, idiopathic clubfoot is uncommon. In the review we describe reconstructive surgery in recurrent deformity of idiopathic clubfoot. Material and methods Surgery may be justified at different age and according to the type of deformity. Different surgical approaches and their indications are exposed in the article. Results After Ponseti's method application additional surgeries may be considered in recurrent clubfoot deformity which may represent 10 to $20 \%$ of cases: second Achilles tenotomy, postero-lateral relapse, complete antero-medial and postero-lateral relapse, transfer of the anterior tibial tendon, correction of sequelae: metatarsus varus, residual equinus, residual rotation of the calcaneopedal unit. Conclusion Idiopathic equine varus clubfoot is a frequent condition. Well-codified management should lead to extremely favorable functional results. Unfortunately, some cases lead to a recurrence of the deformity. Surgical procedures are sometimes required. The goal is to avoid as much as possible arthrodesis and secondary degenerative arthritis.
\end{abstract}

Keywords: clubfoot relapse, surgical treatment

\section{INTRODUCTION}

Despite the good knowledge of anatomical lesions in congenital clubfoot [1], and despite the appropriate understanding of conservative methods of correction, surgery remains sometimes indicated. The operation should not be seen as a complication of insufficient treatment, but as a plus to further improve the functional result. Surgery must be discussed with the parents during the antenatal visit to avoid anxieties and unpleasant surprises during the long follow-up of the child.

Recurrent clubfoot deformity may be due to either an imperfect initial correction, or a natural history of a severe disease. In the latter, idiopathic clubfoot is uncommon. Etiology of such clubfoot is most often a neuromuscular disorder like spina bifida, arthrogryposis, myopathy, spinal amyotrophy, dystonia.

Nevertheless, we will describe in this chapter reconstructive surgery in recurrent deformity of idiopathic clubfoot. Surgery may be justified at different

\section{RESULTS AND DISCUSSION}

\section{Achilles tenotomy}

\subsection{Indication}

The goal of the Achilles tenotomy is to achieve an ankle dorsiflexion greater than $20^{\circ}$. So, its main indication concerns cases of insufficient dorsiflexion of the ankle at the end of the cast series. Nevertheless, some surgeons do it routinely in every case [4]. In case of doubt, a lateral X-ray of the ankle in maximal dorsiflexion may be decisive. A reasonable attitude is to perform the Achilles tenotomy if the tibio-calcaneal angle is greater than $65^{\circ}$.

In case of a recurrent equinus, the same goal should be obtained and may justify a second tenotomy. But necessity for a second tenotomy remains very rare or it age and according to the type of deformity.

According to Ponseti's method, Achilles tenotomy is considered as part of the initial treatment of most clubfeet and is performed at a mean age 6 weeks after a series of corrective casts [2]. It is accepted that a deficit of $10^{\circ}$ of dorsal flexion of the ankle justifies the Achilles tenotomy. Then, further surgeries may be considered in case of recurrent clubfoot deformity which may represent 10 to $20 \%$ of cases, as well as in some sequelae [3]:

- second Achilles tenotomy;

- postero-lateral relapse;

- complete antero-medial and postero-lateral relapse;

- transfer of the anterior tibial tendon;

- correction of sequalae: metatarsus varus, residual equinus, residual rotation of the calcaneopedal unit.

Or goal is to describe the technique of surgical procedures and their indications in recurrent clubfeet. 
perceived. An above the knee cast is configured in the corrective position, which means $60^{\circ}$ of lateral rotation and at least $10^{\circ}$ of dorsiflexion of the ankle. It is replaced two weeks later by another cast for another two weeks.

When equinus persists after 3-4 months of age despite a new series of corrective cast, a second Achilles tenotomy may be performed by some surgeons. The procedure can be comparable with the above description and follow-up is equivalent [7]. But, as the healing process after the first tenotomy often leads to a thick tendon, an open approach may be preferable. Then, a " $Z$ " lengthening is performed. The shape of the " $\mathrm{Z}$ " lengthening may consider cutting the medial fibres of the distal tendon in order to decrease the varus effect of the medial insertion.

\section{Anterior tibialis tendon transfer}

\subsection{Indication}

The goal of the anterior tibialis tendon transfer is to correct a residual dynamic supination of the forefoot when walking. This is sometimes justified in some welltreated feet because the negative action of the anterior tibialis muscle persists. Indeed, a residual supination of the forefoot at walk may be just due to the retraction of the tendon insufficiently corrected by previous treatments. Thus, the indication of a transfer of this tendon can reach nearly $30 \%$ of children around the age of 6 years according to certain series [7-9]. Before deciding on this surgical act, two to three corrective casts are useful. They can sometimes lead to a significant improvement and avoid this operation. Whenever possible, gait analysis provides useful information.

Some surgeon prefers a hemi transfer to a total transfer of the tendon. The fear is to create hypercorrection in pronation of the forefoot. Hyper pronation may appear when the transfer is performed through the cuboid bone which is in a too lateral position. But as the lateral cuneiform bone is selected, it seems that a total transfer of the tendon gives better results than its hemi transfer.

\subsection{Surgical technique}

\subsubsection{Total transfer}

This procedure consists of transferring the anterior tibialis tendon from its medial cuneo-metatarsal insertion onto the lateral cuneiform. The distal insertion of the tendon is detached through a small longitudinal skin incision. By a second incision on the anterior aspect of the distal third of the leg, and after having incised the fascia, the anterior tibialis tendon is pulled out. A third skin incision is made above the lateral cuneiform. Using a long forceps, the tendon should be passed from proximal to distal under the anterior retinaculum. A Kirschner wire is pushed in the middle of the lateral cuneiform, its good position is controlled with a C-arm. A 5-mm cannulated drill is used. Then the tendon is sutured, a long needle is pulled through the sole of the foot, and the tendon is strongly buried into the cuneiform bone. The migration of the tendon is improved by the maximal dorsiflexion of the foot. Then, the fixation of the tendon is obtained either by a plantar button, or by various implants as staple, anchor, and preferably absorbable screw (Fig. 1).

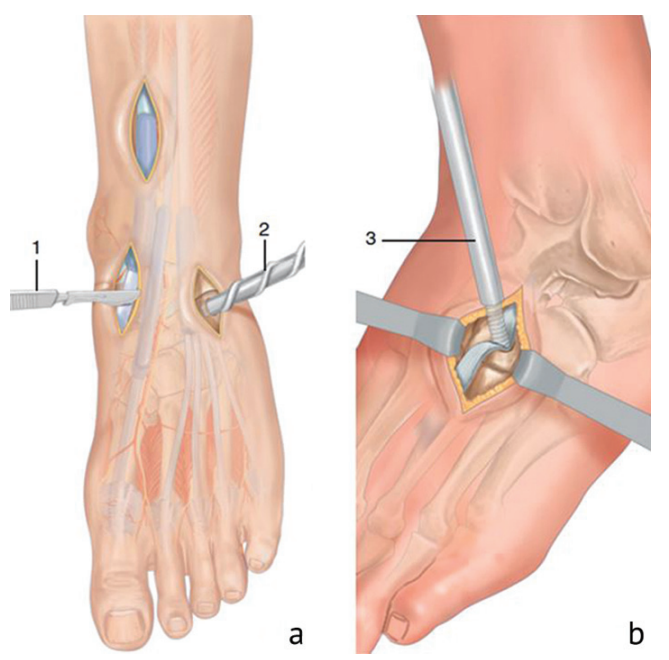

Fig. 1 Technique of transfer of the anterior tibialis tendon to the lateral cuneiform bone: the tendon is detached from its distal insertion while the lateral cuneiform bone is drilled (a); the tendon is passed below the retinaculum and fixed by an interference screw (b) [3]

\subsubsection{Hemi transfer}

In this procedure, the distal medial part of the tendon is not detached, which is not logic as we consider the negative effect of the retracted muscle. Nevertheless, through the first and the second incisions, the tendon is longitudinally split, its lateral portion is detached and then is passed below the retinaculum to be finally fixed into the cuneiform bone as previously described.

\section{Surgical soft tissue release}

\subsection{Principle and indication}

The compliance of wearing Denis Browne splints and the quality of the medical supervision are extremely important [10-13]. If wearing is accepted, the recurrence rate is approximately $14 \%$, for $67 \%$ of recurrence with a third of surgical revision in the event of poor acceptance. In other words, the recurrence rate is $60 \%$ if splints are abandoned at 2 years old, $20 \%$ at 3 years old and $10 \%$ at 4 years old.

Knowing the poor results of extensive soft tissue releases in infants once the end of growth has been obtained, everything must be done to reduce the number of surgical procedures, which is observed by many teams [14].

The principle of "surgical releases" corresponds to the release of the posterolateral fibrous node and then possibly of the anteromedial fibrous node [1]. A good knowledge of the pathological anatomy makes it possible to adapt the surgery. Different approaches exist, each with advantages and disadvantages: the large posteromedial release described by Turco, the posterior Cincinnati approach, the double posterolateral and medial approach (Fig. 2). "A la carte" surgery is therefore possible as it targets only to pathological structures [15].

The soft tissue release was one of the usual approaches till the 1990s, and it is only justified today in certain indications in children after the age of walking. Release is justified when alternative with a new series of cast is unsuccessful. Equinus of $10^{\circ}$ and/or varus of $10^{\circ}$ or more are good indications for a soft tissue release. 


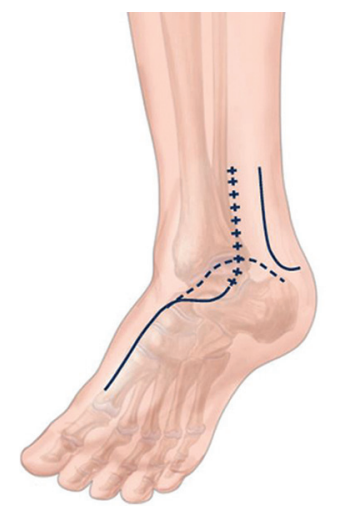

+++ Turcot's approach
---- Cincinatti's incision
+ double incision

\subsection{Surgical techniques [16]}

\subsubsection{The posterolateral release}

The child is operated in a prone position as most of the surgery needs a perfect view of posterior structures. A tourniquet is used.

The posterolateral release is performed through a posterior skin incision, either vertical in a "J" shape or horizontal Cincinatti's in its posetrolateral part. The dissection of the Achilles tendon allows its section in a "Z" shape, with a division of the distal medial fibres. The vertical split should measure $3 \mathrm{~cm}$ to allow a mean lengthening of one centimeter. Then, the retracted posterolateral retinaculum which maintain closed the lateral malleolus to the calcaneum is cut. The final correction of the equinus is obtained after the section of the posterior talocrural capsule, the posterior talo-fibular and the calcaneo-fibular ligaments (Fig. 3). It is not necessary to open the posterior subtalar capsule because its section doesn't improve the correction of the varus and it increases the risk of a posterior avascular necrosis of the talus. Sometimes, a lengthening of the flexor hallux tendon is required: to avoid suture, the tendon is simply cut in its portion surrounded by muscle fibres. Doing so, there is no division of the muscle-tendon.

Then, the talo-calcaneal divergence is controlled under the $\mathrm{C}$-arm and should reach at least $30^{\circ}$. If the divergence is not sufficiently obtained, it is possible to introduce a Kirschner wire posteriorly into the talus bone and use it as a "joystick" to correct the position of the talus. The wire is then pushed into the navicular bone and towards the medial column while the calcaneo-pedal block is corrected in the maximal lateral rotation (Fig. 4).

\subsubsection{The antero-medial release}

If it is not possible to re-establish an anatomical talocalcaneal relationship, a second medial skin incision on the foot or the medial part of the Cincinatti's is performed. Then, both posterior and anterior tibialis tendons are lengthened. The lengthening of the posterior tibialis tendon needs to detach its navicular insertion, and to dissect its plantar tendon which is separated from the plantar surface of cuneiform bones. This distal part of the tendon will be fixed later on the navicular bone. The lengthening of the anterior tibialis tendon is made by a " $\mathrm{Z}$ " lengthening plasty. Then, the talonavicular capsule is open, the "spring ligament" is released, and, according to the needs, the calcaneo-cuboid plantar joint is open. In case of severe metatarsus varus, it is necessary to shorten the external arch of the foot either by removing a bony wedge at the lateral base of the calcaneus (Lichtblau), or by making a closed wedge osteotomy of the cuboid (Fig. 5). The shortening of the lateral arch is performed via the same medial plantar approach and doesn't need a third lateral skin incision of the foot.
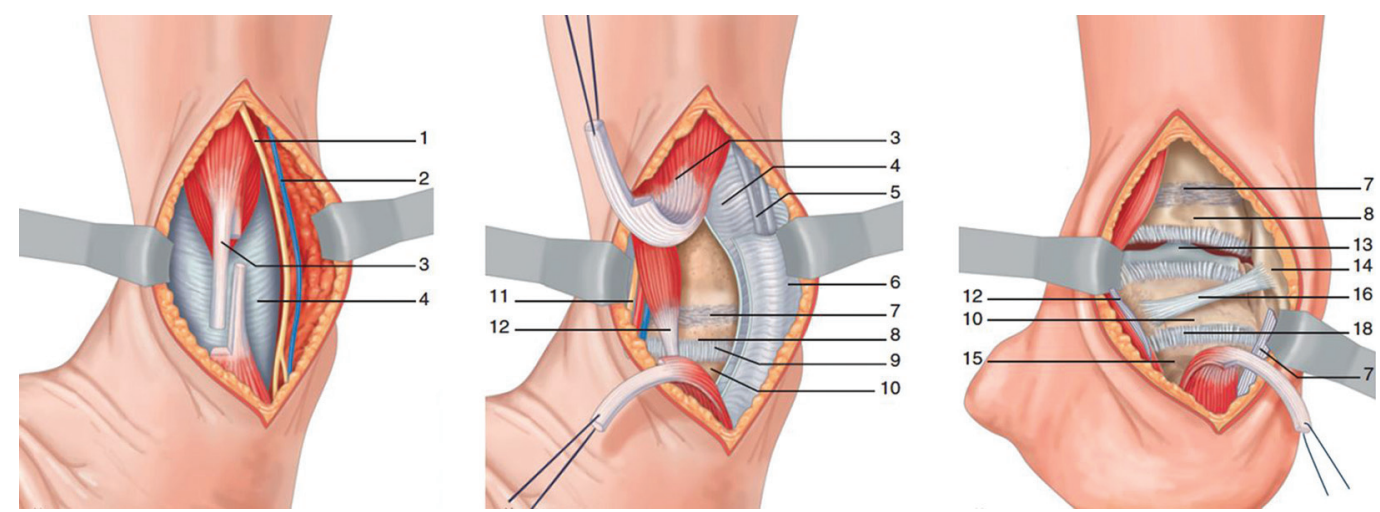

Fig. 3 Soft tissue release by a postero-lateral approach [3]. Legends: 1 - lateral saphenous nerve, 2 - lateral saphenous vein, 3 - Achilles tendon, 4 - deep posterior fascia, 5 - fibular tendons, 6 - fibular tendon sheath, 7 - distal tibial physis, 8 - distal tibial epiphysis, 9 - talocrural joint capsule, 10 - talus bone, 11 - posterior tibial vasculo-nervous bundle, 12 - flexor hallucis muscle, 13 - dome of talus bone, 14 - lateral malleolus, 15 - calcaneus, 16 - posterior talofibular ligament, 17 - calcaneofibular ligament, 18 - talo-calcaneal joint capsule
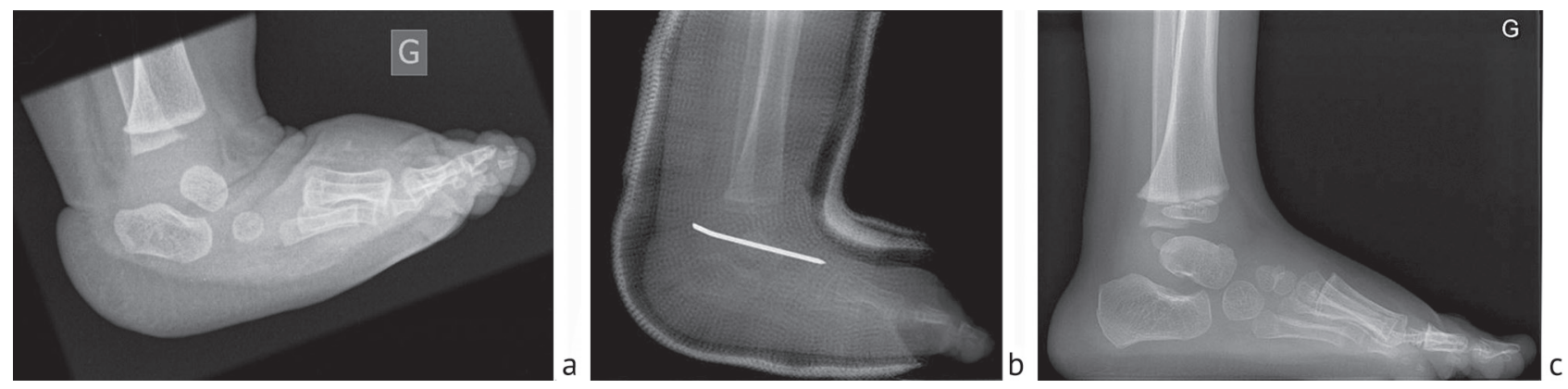

Fig. 4 Iatrogenic convex deformity at the age of 8 months following an inappropriate rehabilitation of a clubfoot (a); posterolateral release and talo-calcaneal alignment (b); at the age of three, sequelae deformity of the dome of the talus bone (c) 

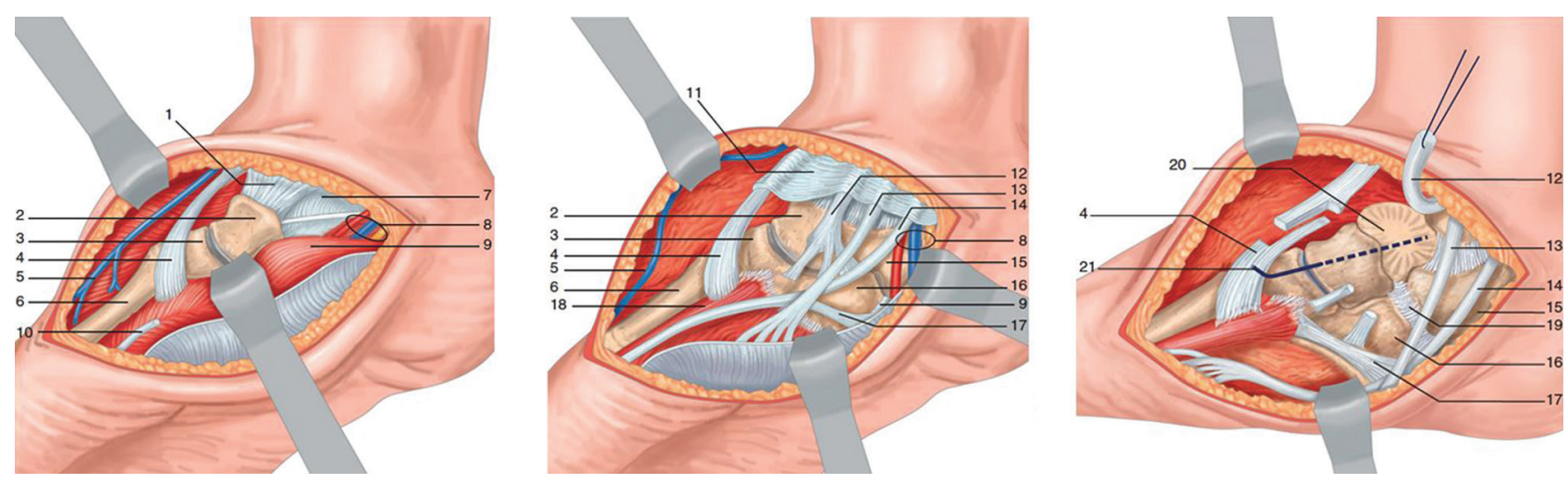

Fig. 5 Soft-tissue release by an anteromedial approach [3]. Legend: 1 - talo-crural deltoid ligament (superficial), 2 - navicular bone, 3 - medial cuneiform bone (1st), 4 - anterior tibialis tendon, 5 - saphenous vein, 6 - first metatarsal, 7 - medial collateral ligament (deep), 8 - posterior tibial vasculo-nervous bundle, 9 - hallux abductor muscle, 10 - hallux abductor muscle tendon, 11 - anterior retinaculum, 12 - posterior tibial tendon, 13 - flexor hallucis tendon, 14 - flexor hallucis tendon, 15 - calcaneus, 16 - cuboid bone, 17 - peroneal longus tendon, 18 - flexor hallucis brevis muscle, 19 - calcaneo-cuboid joint, 20 - head of the talus bone, 21 - talo-navicular pin

\subsubsection{End of the procedure}

At the end of the release, the correction is usually maintained by two $\mathrm{K}$ wires. One $\mathrm{K}$ wire is pushed form posterior to anterior into the talus, then navicular bone and medial column. During this manoeuvre, the calcaneo-pedal block is pushed in abduction as much as possible. The second $\mathrm{K}$-wire is pushed though the calcano-cuboid joint and the lateral column to maintain the correction of the metatarsus varus. It is not necessary to add some calcaneo-talo-crural wires as the correction of the equinus is maintain into the post-operative cast.

The tendons are sutured as follow: the anterior tibialis tendon is sutured with a mean lengthening of 8 to $10 \mathrm{~mm}$; the plantar part of the posterior tibialis tendon is fixed on the navicular bone with a mean lengthening of 8 to $10 \mathrm{~mm}$. Finally, the Achilles tendon is sutured with a mean lengthening of 8 to $12 \mathrm{~mm}$. The correct length is selected when the tendon is in tension with a $0^{\circ}$ dorsiflexion of the ankle.

The quality of haemostasis during the surgery is of importance, drainage is placed for 48 hours, and the skin incisions are closed in two layers with resorbable sutures. Because post-operative swelling is important, a first dressing is performed with a posterior splint in dorsiflexion. After 2 days, a cast is made in a good position. This cast is changed after one week to improve the dorsiflexion of the foot. This is the reason to avoid some transplantar K-wires. After 6 weeks, the cast is removed, and splints and physiotherapy are prescribed.

\section{Neglected clubfoot}

Neglected club feet are those that could not benefit from the treatment described above as soon as possible. The children then consult several years after the acquisition of the walk, the deformations of their feet are very severe, and stiffness has set in. Typically, these children walk on their dorsal feet. Treatment according to Ponseti is always offered as a first-line treatment with favourable outcomes sometimes. But in case of failure, a surgical attitude should be proposed [17].

The advantages of the Ilizarov method are related to the possibility of gradually correcting deformities of the foot using an external fixator. This evidence justifies the application of the technique in the correction of inveterate or neglected PBVE, especially for feet that have already undergone numerous surgeries [7, 18-22]. Vascular problems, scar adhesions, early arthritis of the talonavicular joint, subtalar and mid-tarsal joints make progressive corrections preferable to extemporaneous corrections [23-27]. This method is aimed at older children and adolescents and must obtain their approval and cooperation in the therapeutic project.

The treatment with the Ilizarov's technique is described by Dimitri Popkov in another chapter of this issue.

\section{Surgery of sequelae}

\subsection{Metatarsus varus}

In the presence of an inveterate metatarsus varus, we should avoid the shortening osteotomy of the lateral column of the foot. So, a lengthening of the medial column is associated with an osteotomy of the proximal metaphysis of the middle metatarsals [28]. This intervention can be performed by two short, minimally invasive approaches [29] (Fig. 6). In children up to age 6 , a capsulotomy of the cuneo-metatarsal joint opens the joint (1st ray). The growth remodelling will correct the shape of the cuneiform within few years. In older children, an addition wedge osteotomy of the medial cuneiform is preferable.
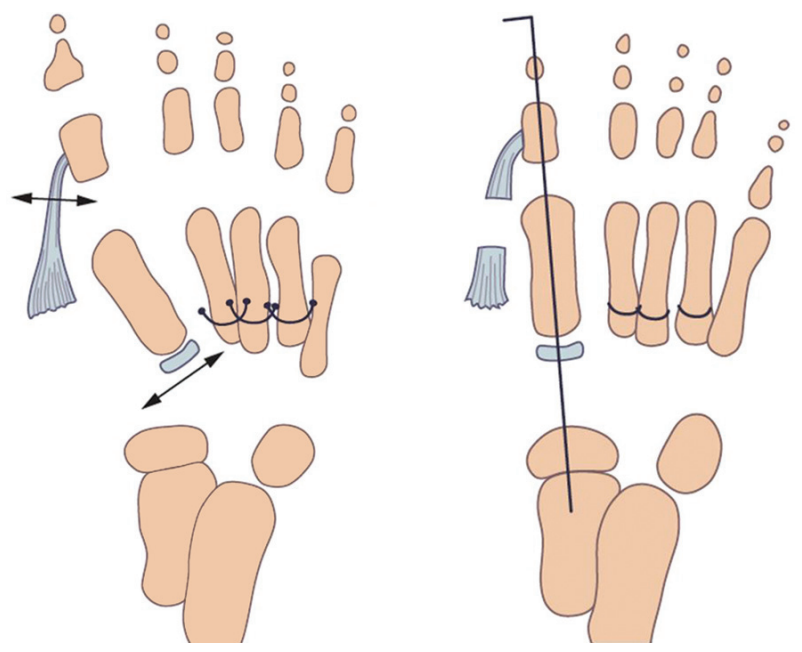

Fig. 6 Diagram of the correction of the metatarsus varus according to Cahuzac [28]. Opening of the medial cuneometatarsal joint capsule and osteotomy of the proximal metaphysis of the three middle metatarsals [3] 


\subsection{Irreducible equinus}

A $10^{\circ}$ ankle dorsiflexion is necessary for an almost normal walk. When equinus persists, it is usually associated to a flat dome of the talus. Surgical of the flat dome is not possible. So, residual equinus can be corrected by a recurvatum osteotomy of the distal tibia.

After the end of growth, a tibiofibular dorsiflexion closed wedge osteotomy is performed. Through an antero lateral approach, an anterior bone wedge of 10 $15^{\circ}$ of the tibia is removed 3 to $4 \mathrm{~cm}$ above the joint. An oblique osteotomy of the fibula is mandatory. A partial resection of the fibula avoids a posterior bump. The fixation of the tibia is obtained with an anterior screw plate (Fig. 7).
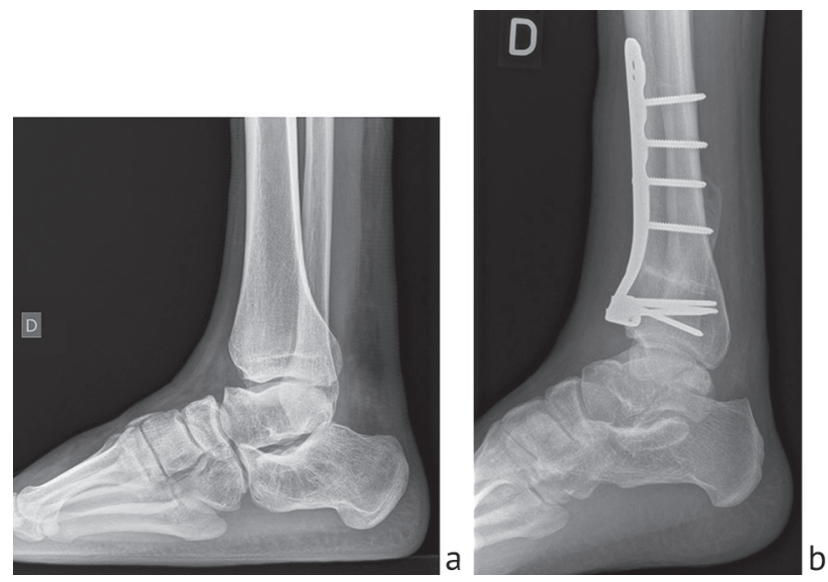

Fig. 7 18-year-old boy with pain at walk due to equinus after treatment of clubfoot; the talo-crural joint is deformed with a flattened talus dome. $15^{\circ}$ recurvatum tibial osteotomy. Lateral $\mathrm{X}$-rays pre-operative (a) and one-year post-operative (b)

The osteotomy, whatever its method, seems to be more effective than a modulation of growth obtained by two "8 plates" placed on the anterior aspect of the distal tibia [30] (Fig. 8).
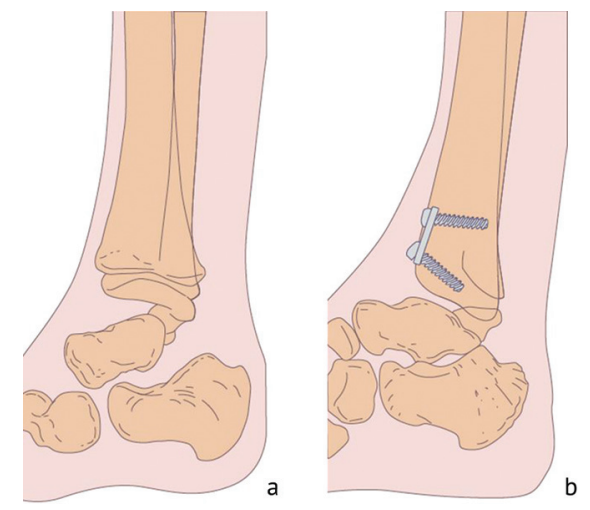

Fig. 8 Distal anterior tibial "8 plates" to improve the dorsal flexion by growth modulation: pre-operative (a) and postoperative views (b) [3]

\section{block}

5.3. Irreducible medial rotation of the calcaneo-pedal

In the presence of complex sequelae deformities, several approaches are offered to the surgeon.

- The Souchet's curvilinear calcaneal osteotomy is an osteotomy of the calcaneus located below the subtalar joint. This elegant technique allows the derotation of the calcano-pedal block without affecting the subtalar joint [31].

- Talectomy, naviculectomy, double subtalar and mediotarsal arthrodesis are aggressive procedures whose mid-term course is marked by joint pain and signs of degenerative arthritis. Also, these classic procedures are becoming increasingly rarely justified. They can be replaced by modeling osteotomies to correct, for example, a residual foot cavus.

\section{CONCLUSION}

Idiopathic equine varus clubfoot is a frequent condition. Well-codified management should lead to extremely favorable functional results. Unfortunately, some cases lead to a recurrence of the deformity. New series of cast may correct these conditions and obtain satisfactory results. However, surgical procedures are sometimes required: second Achilles tendon lengthening, transfer of the anterior tibialis tendon, release of the soft tissues, osteotomies. The goal is to avoid as much as possible arthrodesis and secondary degenerative arthritis. Because rigorous monitoring of club feet until the end of growth is done, early screening of recurrence is performed, and appropriate treatment is proposed allowing improvement of the function in adulthood.

\section{REFERENCES}

1. Seringe R., Wicart P.; French Society of Pediatric Orthopaedics. The talonavicular and subtalar joints: the "calcaneopedal unit" concept. Orthop. Traumatol. Surg. Res., 2013, vol. 99, no. 6 Suppl., pp. S345-S355. DOI:10.1016/j.otsr.2013.07.003.

2. Böhm S. Special symposium issue: Clubfoot. J. Child. Orthop., 2019, vol. 13, no. 3, pp. 236-237. DOI: 10.1302/1863-2548.13.190300

3. De Coulon G., Bonnefoy A., Leonchuk S., Popkov D., Lascombes P.F.M. Chirurgie du pied bot varus équin idiopathique [Idiopathic equine varus clubfoot surgery]. EMC - Podologie. Paris : Elsevier. 2019. Article 27-050-A-40. DOI: 10.1016/S0292-062X(19)47911-7. (in French)

4. Marleix S., Chapuis M., Fraisse B., Tréguier C., Darnault P., Rozel C., Rayar M., Violas P. Idiopathic club foot treated with the Ponseti method. Clinical and sonographic evaluation of Achilles tendon tenotomy. A review of 221 club feet. Orthop. Traumatol. Surg. Res., 2012, vol. 98, no. 4 Suppl., pp. S73-S76. DOI: 10.1016/j.otsr.2012.03.001.

5. Ponseti I.V., Zhivkov M., Davis N., Sinclair M., Dobbs M.B., Morcuende J.A. Treatment of the complex idiopathic clubfoot. Clin. Orthop. Relat. Res., 2006, vol. 451, pp. 171-176. DOI: 10.1097/01.blo.0000224062.39990.48.

6. Ponseti I.V. Treatment of congenital club foot. J. Bone Joint Surg. Am., 1992, vol. 74, no. 3, pp. 448-454

7. Eidelman M., Kotlarsky P., Herzenberg J.E. Treatment of relapsed, residual and neglected clubfoot: adjunctive surgery. J. Child. Orthop., 2019, vol. 13, no. 3, pp. 293-303. DOI: 10.1302/1863-2548.13.190079.

8. Gray K., Burns J., Little D., Bellemore M., Gibbons P. Is tibialis anterior tendon transfer effective for recurrent clubfoot? Clin. Orthop. Relat. Res., 2014, vol. 472, no. 2, pp. 750-758. DOI: 10.1007/s11999-013-3287-X.

9. Zionts L.E., Jew M.H., Bauer K.L., Ebramzadeh E., Sangiorgio S.N. How many patients who have a clubfoot treated using the Ponseti method are likely to undergo a tendon transfer? J. Pediatr. Orthop., 2018, vol. 38, no. 7, pp. 382-387. DOI: 10.1097/BPO.0000000000000828.

10. Van Gelder J.H., van Ruiten A.G., Visser J.D., Maathuis P.G. Long-term results of the posteromedial release in the treatment of idiopathic clubfoot. J. Pediatr. Orthop., 2010, vol. 30, no. 7, pp. 700-704. DOI: 10.1097/BPO.0b013e3181ec9402.

11. Alves C. Bracing in clubfoot: do we know enough? J. Child. Orthop., 2019, vol. 13, no. 3, pp. 258-264. DOI: 10.1302/1863-2548.13.190069. 
12. Zionts L.E., Dietz F.R. Bracing following correction of idiopathic clubfoot using the Ponseti method. J. Am. Acad. Orthop. Surg., 2010, vol. 18, no. 8, pp. 486-493. DOI: 10.5435/00124635-201008000-00005.

13. Goldstein R.Y., Seehausen D.A., Chu A., Sala D.A., Lehman W.B. Predicting the need for surgical intervention in patients with idiopathic clubfoot. J. Pediatr. Orthop., 2015, vol. 35, no. 4, pp. 395-402. DOI: 10.1097/BPO.0000000000000282.

14. Halanski M.A., Davison J.E., Huang J.C., Walker C.G., Walsh S.J., Crawford H.A. Ponseti method compared with surgical treatment of clubfoot: a prospective comparison. J. Bone Joint Surg. Am., 2010, vol. 92, no. 2, pp. 270-278. DOI: 10.2106/JBJS.H.01560.

15. Bensahel H., Csukonyi Z., Desgrippes Y., Chaumien J.P. Surgery in residual clubfoot: one-stage medioposterior release "à la carte". J. Pediatr. Orthop., 1987, vol. 7, no. 2, pp. 145-148. DOI: 10.1097/01241398-198703000-00005.

16. Lascombes P. Le pied bot varus équin congénital idiopathique [Congenital idiopathic equine varus clubfoot]. Conférences d'Enseignement. Cahier $d^{\prime}$ Enseignement de la SOFCOT. $n^{\circ} 38$. Expansion Scientifique Française [Scientific Conference of SOFCOT No 38]. Elesevier, Paris. 1990. P. 67-84. (in French)

17. Khan S.A., Kumar A. Ponseti's manipulation in neglected clubfoot in children more than 7 years of age: a prospective evaluation of 25 feet with long-term follow-up. J. Pediatr. Orthop. B, 2010, vol. 19, no. 5, pp. 385-389. DOI: 10.1097/BPB.0b013e3283387cc8.

18. Bradish C.F., Noor S. The Ilizarov method in the management of relapsed club feet. J. Bone Joint Surg. Br., 2000, vol. 82, no. 3, pp. 387-391. DOI: $10.1302 / 0301-620 x .82 b 3.9689$.

19. El-Sayed M. Ilizarov external fixation for management of severe relapsed clubfeet in older children. Foot Ankle Surg., 2013, vol. 19, no. 3, pp. 177-181. DOI: $10.1016 /$ j.fas.2013.04.002.

20. Khanfour A.A. Ilizarov techniques with limited adjunctive surgical procedures for the treatment of preadolescent recurrent or neglected clubfeet. J. Pediatr. Orthop. B, 2013, vol. 22, no. 3, pp. 240-248. DOI: 10.1097/BPB.0b013e32835f1f99.

21. Tripathy S.K., Saini R., Sudes P., Dhillon M.S., Gill S.S., Sen R.K., Agarwal A., Dhatt S., Mootha A.K. Application of the Ponseti principle for deformity correction in neglected and relapsed clubfoot using the Ilizarov fixator. J. Pediatr. Orthop. B, 2011, vol. 20, no. 1, pp. 26-32. DOI: 10.1097/ BPB.0b013e32833f33fe.

22. Van Bosse H.J. Treatment of the neglected and relapsed clubfoot. Clin. Podiatr. Med. Surg., 2013, vol. 30, no. 4, pp. 513-530. DOI: 10.1016/j.cpm.2013.07.006.

23. Fernandes R.M., Mendes M.D., Amorim R., Preti M.A., Sternick M.B., Gaiarsa G.P. Surgical treatment of neglected clubfoot using external fixator. Rev. Bras. Ortop., 2016, vol. 51, no. 5, pp. 501-508. DOI: 10.1016/j.rboe.2016.08.002.

24. Ilizarov G.A., Shevtsov V.I., Kuz'min NV. Sposob lecheniia ékvinopoloi deformatsii stopy [Method of treating talipes equinocavus]. Ortop. Travmatol. Protez., 1983, no. 5, pp. 46-48. (in Russian).

25. Laville J.M., Collin J.F. Traitement du pied bot varus équin récidivé ou négligé par appareil d'Ilizarov [Treatment of recurrent or neglected clubfoot by the Ilizarov appratus]. Rev. Chir. Orthop. Reparatrice Appar. Mot., 1992, vol. 78, no. 7. P. 485-490. (in French)

26. Eidelman M., Keren Y., Katzman A. Correction of residual clubfoot deformities in older children using the Taylor spatial butt frame and midfoot Gigli saw osteotomy. J. Pediatr. Orthop., 2012, vol. 32, no. 5, pp. 527-533. DOI: 10.1097/BPO.0b013e318259ff2d.

27. Ganger R., Radler C., Handlbauer A., Grill F. External fixation in clubfoot treatment - a review of the literature. J. Pediatr. Orthop. B, 2012, vol. 21, no. 1, pp. 52-58. DOI: 10.1097/BPB.0b013e32834adba7.

28. Cahuzac J.P., Laville J.M., de Gauzy J.S., Lebarbier P. Surgical correction of metatarsus adductus. J. Pediatr. Orthop. B, 1993, vol. 2, no. 2, pp. $176-181$.

29. Knörr J., Soldado F., Pham T.T., Torres A., Cahuzac J.P., de Gauzy J.S. Percutaneous correction of persistent severe metatarsus adductus in children. J. Pediatr. Orthop., 2014, vol. 34, no. 4, pp. 447-452. DOI: 10.1097/BPO.0000000000000122.

30. Al-Aubaidi Z., Lundgaard B., Pedersen N.W. Anterior distal tibial epiphysiodesis for the treatment of recurrent equinus deformity after surgical treatment of clubfeet. J. Pediatr. Orthop., 2011, vol. 31, no. 6, pp. 716-720. DOI: 10.1097/BPO.0b013e31822109b6.

31. Souchet P., Ilharreborde B., Fitoussi F., Morel E., Bensahel H., Penneçot G.F., Mazda K. Calcaneal derotation osteotomy for clubfoot revision surgery. J. Pediatr. Orthop. B, 2007, vol. 16, no. 3, pp. 209-213. DOI: 10.1097/01.bpb.0000236227.99077.28.

Received: 12.05 .2021

\section{Information about the authors:}

1. Pierre Lascombes, Honorary Professor University of Nancy, France; Past Professor, University of Geneva, Switzerland, Email: pierrelascombes@gmail.com

2. Dmitry A. Popkov, M.D., Ph.D., Professor of RAS, correspondent member French Academy of Medical Sciences, Ilizarov National Medical Research Centre for Traumatology and Orthopedics, Kurgan, Russian Federation, ORCID: 0000-0002-8996-867X,

Email: dpopkov@mail.ru

3. Sergei S. Leonchuk, M.D., Ph.D., Ilizarov National Medical Research Centre for Traumatology and Orthopedics, Kurgan, Russian Federation, Email: leon4yk@mail.ru 